\title{
INFLUÊNCIA DA CAMADA DE IMPEDIMENTO NO SOLO SOBRE O CRESCIMENTO DE Eucalyptus grandis (Hill) ex Maiden*
}

\section{SOIL IMPERVIOUS LAYER INFLUENCE ON Eucalyptus grandis GROWTH RATE}

\author{
César Augusto Guimarães Finger ${ }^{1}$ Mauro Valdir Schumacher ${ }^{1}$ Paulo Renato Schneider $^{2}$ \\ Juarez Martins Hoppe ${ }^{3}$
}

\section{RESUMO}

O objetivo deste trabalho foi avaliar a influência da camada de impedimento no solo, sobre a sobrevivência e o crescimento em diâmetro a altura do peito e altura de plantas de Eucalyptus grandis (Hill) ex. Maiden. Os tratamentos de preparo do solo foram solo subsolado (T1) e não subsolado (T2). Após 12, 24, 36 e 43 meses do plantio, os resultados indicaram haver uma diferença positiva, em todas as variáveis medidas, em prol das mudas plantadas em área subsolada, embora, estatisticamente, não tenha havido diferença significativa entre os tratamentos.

Palavras-chave: Camada de impedimento, subsolagem, crescimento, Eucalyptus.

\section{SUMMARY}

The objective of this work was to evaluate the influence of soil impervious layer about surviving plus diameter and height growth rates of seedlings of Eucalyptus grandis (Hill) ex Maiden. The treatments of soil tillage are subsoiling (T1) and not subsoiling (T2). After 12, 24, 36 and 43 months from planting the results indicated a positive diference in all variables for seedlings planted in area with subsoiling, even so there wasn't significative statistical diference between treatments planted seedling.

Key words: Impervious layer, subsoiling, growth rate, Eucalyptus

1. Engenheiro Florestal, Dr., Prof. Adjunto do Departamento de Ciências Florestais. UFSM. 97.119-900. Santa Maria. RS.

2. Engenheiro Florestal, Dr., Prof. Titular do Departamento de Ciências Florestais. UFSM. 97.119-900. Santa Maria. RS.

3. Engenheiro Florestal, M.Sc., Prof. Adjunto do Departamento de Ciências Florestais. UFSM. 97.119-900. Santa Maria. RS.

* Trabalho financiado pelo CNPq. 


\section{INTRODUÇÃO}

Para que toda e qualquer espécie vegetal possa ter condições ideais de desenvolvimento é necessário que o meio, solo, onde esta será plantada apresente condições mínimas quanto as características físicas e químicas. Quanto as características físicas dos solos, estas podem ser um dos principais fatores limitantes do crescimento e produtividade dos sítios. Em solos que apresentam camadas mais adensadas ou compactadas em decorrência da constante trafegabilidade de máquinas pesadas ou mesmo do pisoteio de animais, é fundamental que se empregue alguma prática de rompimento destas camadas, visando melhorar o ambiente para propiciar uma melhor eficiência de aproveitamento da água e nutrientes por parte do sistema radicular das plantas.

Os eucaliptos são, em geral, árvores de grande plasticidade adaptando-se a diferentes condições ecológicas, embora sejam evidentes as influências do meio sobre seu desenvolvimento. A qualidade do sítio influi não só sobre o crescimento como também sobre a sanidade e sobrevivência das árvores.

A melhoria do sítio através de drenagem, adubação e preparo do solo, entre outras, tem mostrado resultados positivos. Neste sentido, tem se tornado prática comum pelos reflorestadores o uso do subsolador para romper a camada de impedimento do solo, possibilitando uma maior profundidade de enraizamento e melhorando a drenagem, entre outros. Assim, buscando verificar a influência desta prática de preparo de solo, o presente trabalho teve como objetivo comparar a sobrevivência, o crescimento em diâmetro e altura do Eucalyptus grandis implantado sobre solo com camada de impedimento (solo não subsolado) e sobre solo com camada de impedimento rompida (solo subsolado).

\section{REVISÃO DA LITERATURA}

De acordo com MANGIERI \& DIMITRI (1971), o Eucalyptus grandis, tem ocorrência natural ao norte do Estado de Queensland, estendendo-se até Nova Gales do Sul, entre os paralelos $17^{\circ}$ e $35^{\circ}$ de latitude sul respectivamente, e altitude entre 0 e $900 \mathrm{~m}$. Os solos, nestas regiões, são do tipo aluvião, pobres, limosos, francos, ligeiramente enxarcados, sub-solo ligeiramente úmido e argiloso, mas não saturados (GUTTERREZ ,1976).

Segundo FAO (1981), o Eucalyptus grandis, prefere solos profundos, de boa drenagem e se comporta melhor em solos férteis e franco argilosos. A espécie alcança altos incrementos sendo relatado valores até $45 \mathrm{~m}^{3} / \mathrm{ha} /$ ano em sítios bons, mais de $20 \mathrm{~m}^{3}$ sobre sítios médios mesmo em idades maiores de 15 anos. A mesma fonte relata que, em sítios bons, na África do Sul, os incrementos alcançam a cerca de $19 \mathrm{~m}^{3} / \mathrm{ha} /$ ano aos três anos e mais de $45 \mathrm{~m}^{3} / \mathrm{ha} /$ ano aos nove anos. Sobre sítios médios alcançam, aos 3 anos, $11 \mathrm{~m}^{3} /$ ha/ano e $27 \mathrm{~m}^{3} /$ ha/ano na idade de 10 anos e, sobre sítios pobres, cerca de $13 \mathrm{~m}^{3} / \mathrm{ha} /$ ano aos 10 anos.

FINGER (1991), estudando a produção de Eucalyptus grandis na região de Guaíba-RS, também observou a redução da idade de máxima produção física de madeira com o decréscimo da qualidade do sítio. $\mathrm{O}$ autor determinou incrementos médios anuais de $11 \mathrm{~m}^{3} / \mathrm{ha} /$ ano aos 12 anos e de $54 \mathrm{~m}^{3} /$ ha/ano aos 9 anos, em florestas em primeira rotação, respectivamente, para sítios pobres 
e bons. SKOLMEN (1984) e KAPLAN (1989) entre outros, também relatam o decréscimo do período de rotação e o aumento das taxas de incremento médio, com a melhoria da qualidade do sítio.

O sítio caracterizado por HUSCH et al. (1982), como a interação entre fatores climáticos, do solo, topográficos e da competição entre os seres vivos pode até certos limites ser alterado pelo homem através do preparo do solo, adubação, drenagem, irrigação, etc... Assim, o preparo de solo pode modificar as condições ambientais vindo a favorecer o desenvolvimento de uma cultura. No reflorestamento uma prática que tem se tornado freqüente é a subsolagem na linha de plantio, visando não só a diminuição dos custos por não revolver todo o solo da área, e a maior conservação da camada superficial com a redução dos efeitos da erosão, mas principalmente, possibilitar a desestruturação do solo abaixo da superfície, permitindo a penetração das raízes em horizontes mais profundos. Efeitos desta prática no crescimento dos povoamentos já foram registrados por FINGER, (1991). O estudo realizado pelo autor para descrever a produção de povoamentos de Eucalyptus saligna implantados em solo de preparo raso e de preparo profundo mostrou diferenças no desenvolvimento das curvas de índice de sítio, onde solos de preparo raso apresentaram curvas mais achatadas do que as obtidas em solos de preparo profundo.

SCHUMACHER (1995), trabalhando com povoamentos de Eucalytus saligna, E. dunnii e E. globulus, verificou que nos primeiros $30 \mathrm{~cm}$ de profundidade do solo se encontram a maioria das raízes finas das árvores, estas responsáveis pela absorção de água e nutrientes. Este mesmo autor ainda observou que a medida que as raízes finas encontravam uma camada mais adensada, ocorria uma diminuição brusca das mesmas e assim que o solo voltava a apresentar boas condições de permeabilidade ocorria novamente proliferação de raízes finas em camadas bem mais profundas do perfil do solo.

Outro experimento conduzido por POYNTON (1965), também demonstrou que o desenvolvimento de plantas de Eucalyptus saligna aos 6 anos após o plantio foi diretamente relacionado com a intensidade de revolvimento do solo. Árvores que cresciam em locais com solo arado e gradeado em toda a área tiveram desenvolvimento mais vigoroso e tamanho mais uniforme. As plantas de locais com aração e gradagem na linha de plantio tiveram desenvolvimento intermediário e as que cresciam em locais onde o solo foi preparado em sistema de coroa, apresentaram o pior desenvolvimento.

\section{MATERIAL E MÉTODOS}

O experimento foi instalado em área experimental localizada no Campus da Universidade Federal de Santa Maria, em outubro de 1992.

O clima da região é do tipo "Cfa", segundo a classificação climática de Koeppen, ou seja, subtropical úmido, com temperatura média das máximas oscilando em torno de $25^{\circ} \mathrm{C}$ e a média das mínimas ao redor de 15,5 C (MORENO, 1961 e MOTA et al., 1971).

O solo no local está classificado como Podzólico Bruno Acinzentado e se encontra na Unidade de Mapeamento Santa Maria, com textura média, relêvo suavemente ondulado e substrato 
siltito-arenito.

Esta unidade de mapeamento é constituida predominantemente por solos medianamente profundos (em torno de $1 \mathrm{~m}$ ), com cores bruno acinzentadas no horizonte A e bruno amarelados no B, textura média, friáveis e imperfeitamente drenados. Nas profundidades entre 30 e $40 \mathrm{~cm}$ o solo apresenta uma camada bem mais compactada (BRASIL, 1973).

\section{Implantação do experimento}

A área do experimento foi anteriormente utilizada para fins de agricultura e pastoreio, posteriormente abandonada para estas práticas, possibilitando a invasão por capoeiras.

O preparo do solo foi precedido por roçada mecânica em toda a área. Imediatamente após foi iniciado o combate as formigas cortadeiras com o uso de formicida pó e micro-porta-iscas na área do experimento e adjacências.

De acordo com o plano experimental, nas parcelas experimentais que formaram o tratamento 1 , o solo recebeu subsolagem profunda através de um implemento subsolador com profundidade de operação de $60 \mathrm{~cm}$. As linhas de subsolagem foram equidistantes a cada três metros.

O segundo tratamento constou da abertura manual de uma coroa de, aproximadamente, 50 $\mathrm{cm}$ de diâmetro com uma cova simples de $13 \mathrm{~cm}$ de profundidade, no local de plantio da muda.

O espaçamento de plantio foi 3,0 $\mathrm{m}$ entre linhas e 2,0 $\mathrm{m}$ entre plantas na linha.

As parcelas experimentais foram constituidas de 14 plantas úteis e de 22 plantas de bordadura perfazendo um total de 36 árvores de Eucalyptus grandis por parcela. As áreas da parcela, do bloco, e do experimento foram, respectivamete, 216,432 e $1296 \mathrm{~m}^{2}$.

As mudas foram produzidas no viveiro florestal do Departamento de Ciências Florestais da Universidade Federal de Santa Maria e classificadas quanto a altura e vitalidade antes do plantio a campo, visando trazer a maior homogeneidade ao experimento.

Após a implantação do experimento, este foi avaliado diariamente com referência ao ataque por formigas e a sobrevivência, tendo sido necessário a realização de um replantio da ordem de 15 $\%$ nos primeiros 20 dias após o plantio inicial devido ao ataque de formigas. Trinta dias após o plantio, as plantas foram adubadas com NPK na formulação 5-20-20.

A área experimental recebeu ainda duas roçadas mecânicas na entrelinha, sendo a primeira seguida de uma roçada manual na linha de plantio, visando a redução do efeito da mato-competição. Estas operações foram realizadas no sexto mês após o plantio e a segunda seis meses após.

\section{Variáveis resposta}

As variáveis respostas para o experimento foram a sobrevivência das árvores, o diâmetro a altura do peito e a altura total.

As avaliações foram iniciadas 180 dias após o plantio e constituiram-se da avaliação da sobrevivência e da altura das plantas. Esta operação foi repetida quando o experimento completou 12 meses, 24 e 43 meses. A partir do segundo ano iniciaram-se também as medições dos diâmetros 
das árvores.

O delineamento estatístico foi o de blocos casualizados com 2 tratamentos (T1 - solo subsolado e T2 - solo não subsolado) com 3 blocos (repetições).

\section{RESULTADOS E DISCUSSÕES}

Os valores médios observados para as variáveis diâmetro a altura do peito, altura da árvore e a sobrevivência de plantas, nas idades de 6, 12, 24 e 43 meses após o plantio encontram-se na Tabela 1.

As observações dos valores médios apresentados na Tabela 1 evidenciam a grande diferença que existe entre as médias de diâmetro e altura das árvores que crescem em solos subsolados e não subsolados, em qualquer uma das idades consideradas. $\mathrm{O}$ crescimento apresentado pelas plantas de E. grandis em solo subsolado (T1) foi superior em mais de $50 \%$ quanto ao diâmetro a altura do peito (DAP) e, quando considerada a variável altura, mais de $35 \%$ chegando a alcançar $62 \%$ na idade de 24 meses, quando comparado com o valor em solo não subsolado.

TABELA 1: Valores médios de diâmetro a altura do peito, altura e sobrevivência de plantas de Eucalyptus grandis.

\begin{tabular}{c|c|c|c|c|c|c}
\hline SOLO & \multicolumn{3}{|c|}{ SUBSOLADO } & \multicolumn{3}{c}{ NÃO SUBSOLADO } \\
\hline Idade meses & $\begin{array}{c}\mathbf{d} \\
\mathrm{cm}\end{array}$ & $\begin{array}{c}\mathbf{h} \\
\mathrm{m}\end{array}$ & $\begin{array}{c}\text { Sobrev. } \\
\%\end{array}$ & $\begin{array}{c}\mathbf{d} \\
\mathrm{cm}\end{array}$ & $\begin{array}{c}\mathbf{h} \\
\mathrm{m}\end{array}$ & $\begin{array}{c}\text { Sobrev. } \\
\%\end{array}$ \\
\hline 6 & -1 & 1,36 & 100 & -1 & 0,95 & 92,86 \\
12 & -1 & 1,52 & 100 & -1 & 1,12 & 92,86 \\
24 & 3,78 & 3,43 & 97,62 & 2,35 & 2,11 & 92,86 \\
43 & 9,83 & 9,95 & 97,62 & 6,45 & 6,85 & 92,86 \\
\hline
\end{tabular}

Onde: - 1 = Nestas idades, devido a pequena altura das árvores, não foi realizada a medição dos diâmetros.

A avaliação dos resultados de sobrevivência de plantas mostram alta percentagem de plantas vivas nos dois tratamentos testados, embora o tratamento com solo subsolado tenha maior percentagem de plantas vivas, $98,81 \%$, do que o tratamento sem subsolagem, $92,86 \%$, conforme apresentado na Figura 1. 


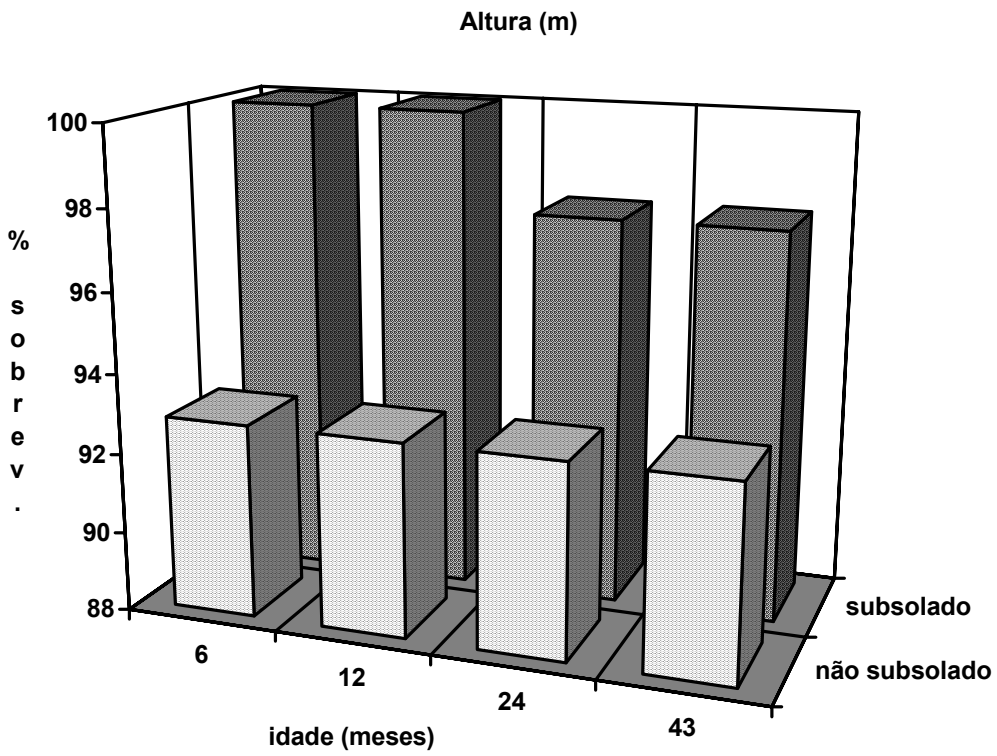

FIGURA 1: Percentagem de sobrevivência de plantas de E. grandis implantado em solo subsolado e não subsolado.

A análise de variância aplicada aos dados levantados a campo para cada variável resposta e idade considerada no experimento, conforme apresentado na Tabela 2, mostrou não haver efeito dos blocos quando consideradas as variáveis diâmetro, altura e sobrevivência de plantio, indicando haver homogeneidade do local onde o experimento esta instalado.

TABELA 2: Resultado da análise de variância entre os tratamentos: solo subsolado e não subsolado, em quatro idades diferentes.

\begin{tabular}{c|c|c|c|c|c|c}
\hline \multirow{2}{*}{$\begin{array}{c}\text { Idade } \\
\text { meses }\end{array}$} & \multicolumn{2}{|c|}{ Diâmetro } & \multicolumn{2}{c|}{ Altura } & \multicolumn{2}{c}{ Sobrevivência } \\
\cline { 2 - 7 } & Trat. & Blocos & Trat. & Blocos & Trat. & Blocos \\
\hline 6 & -1 & -1 & $*$ & $\mathrm{~ns}$ & $\mathrm{~ns}$ & $\mathrm{~ns}$ \\
12 & -1 & -1 & $\mathrm{~ns}$ & $\mathrm{~ns}$ & $\mathrm{~ns}$ & $\mathrm{~ns}$ \\
24 & $\mathrm{~ns}$ & $\mathrm{~ns}$ & $\mathrm{~ns}$ & $\mathrm{~ns}$ & $\mathrm{~ns}$ & $\mathrm{~ns}$ \\
43 & $\mathrm{~ns}$ & $\mathrm{~ns}$ & $\mathrm{~ns}$ & $\mathrm{~ns}$ & $\mathrm{~ns}$ & $\mathrm{~ns}$ \\
\hline
\end{tabular}

Onde: - 1 = Nestas idades, devido a pequena altura das árvores, não foi realizada a medição dos diâmetros; * = Significante ao nível de $95 \%$ de probabilidade de confiança; ns = Não significante ao nível de $95 \%$ de probabilidade de confiança.

O mesmo resultado foi também observado para o efeito dos tratamentos, subsolado e não subsolado, excetuando-se a idade de 6 meses. Este resultado indica não haver efeito da subsolagem sobre o crescimento em diâmetro, altura e sobrevivência de $\boldsymbol{E}$. grandis.

Estes valores, embora não difiram estatísticamente entre si, mostram grande diferença em termos biométricos, devendo produzir maior quantidade de madeira por hectare do que as árvores 
em solo com camada de impedimento.

A não detecção de diferença pela análise de variância entre as médias das variáveis dendrométricas estudadas pode ter sido causada pelo melhor desempenho de uma repetição do tratamento não subsolado (bloco III) quando comparado com o mesmo tratamento nos demais blocos.

No bloco 3, o valor médio alcançado no tratamento não subsolado foi ligeiramente superior ao das outras repetições, embora sempre inferior (cerca de $25 \%$ ) ao valor apresentado no tratamento que sofreu subsolagem o que, trouxe maior discrepância entre os valores observados, podendo ser a causa do resultado encontrado no cálculo de análise de variância.

A observação continuada do crescimento das árvores por mais alguns anos permitirá verificar o comportamento das atuais tendências de crescimento apresentadas de forma gráfica nas Figuras 2 e 3. Nestas figuras é nítida a diferença de crescimento alcançada, tanto em diâmetro quanto para a altura de árvores de Eucalyptus grandis crescendo sobre solo subsolado e não subsolado.

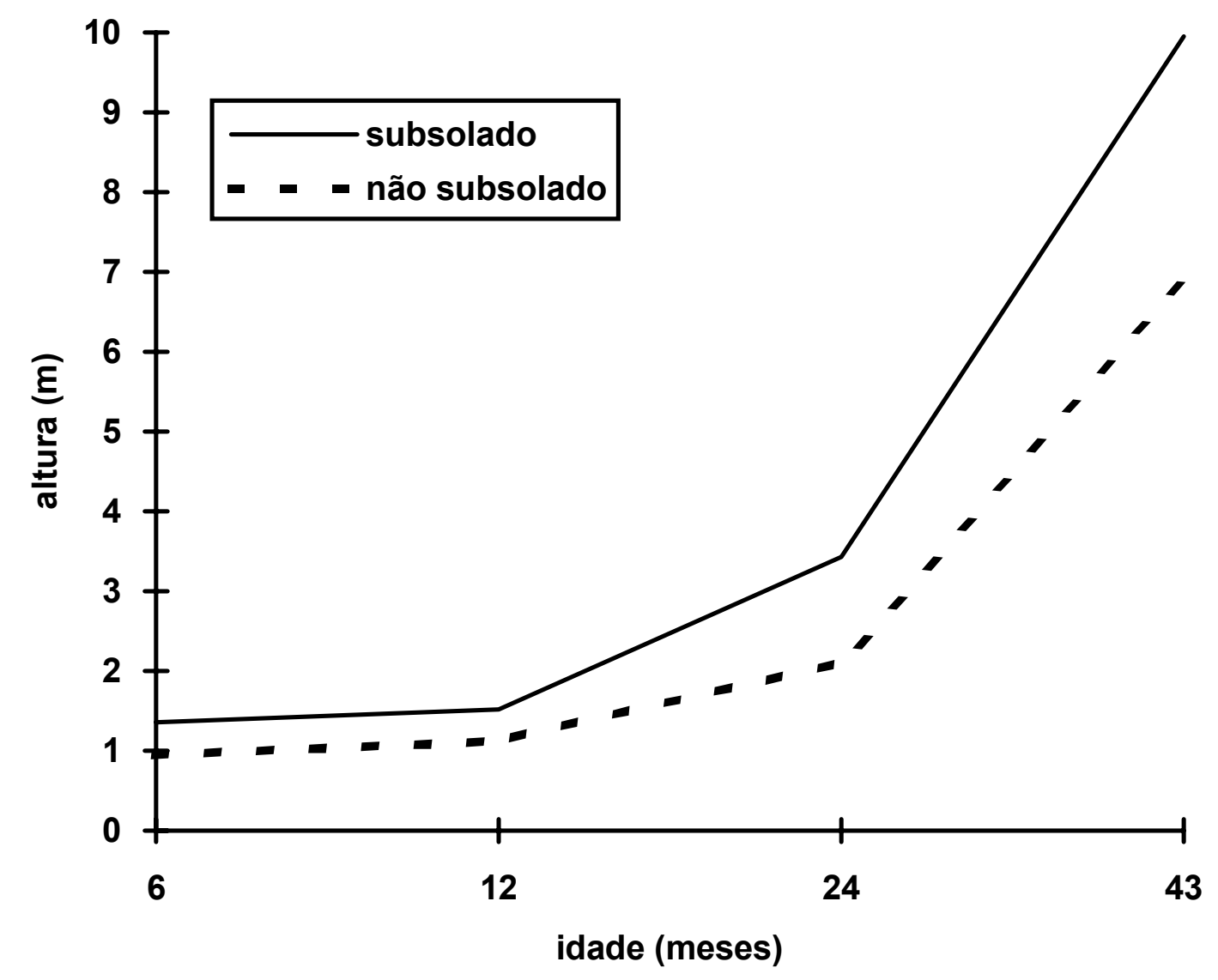

FIGURA 2: Curvas de crescimento de altura de E. grandis crescendo em solo subsolado e não subsolado. 


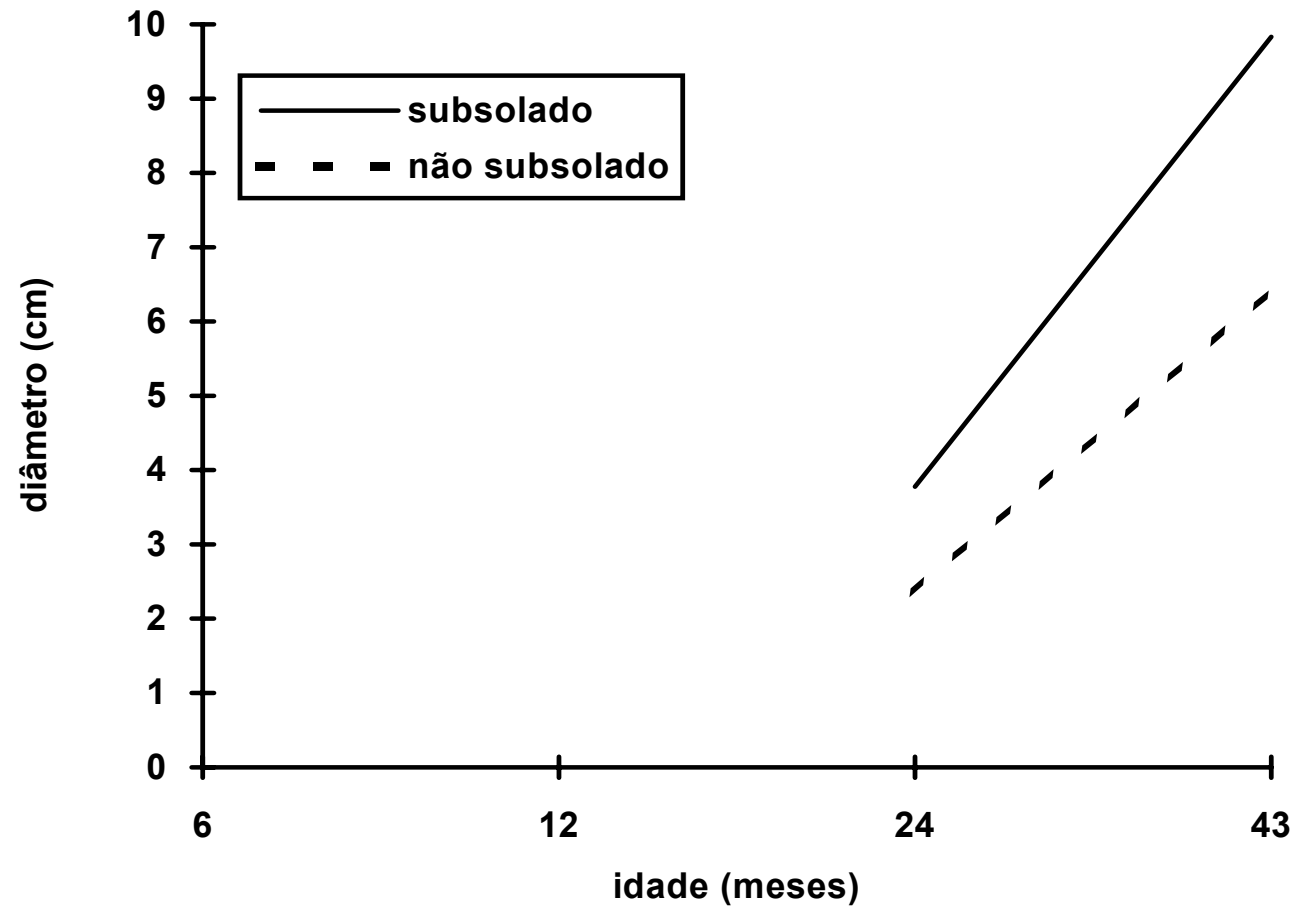

FIGURA 3: Curvas de crescimento de diâmetro de E. grandis crescendo em solo subsolado e não subsolado.

\section{CONCLUSÕES}

O crescimento de Eucalyptus grandis em solo Podzolico Bruno Acinzentado, pertencente a Unidade de Mapeamento Santa Maria, é afetado pela ocorrência de camada de impedimento.

A subsolagem propiciou o maior crescimento de Eucalyptus grandis em diâmetro e altura e ainda, maior sobrevivência das plantas do que em solo não subsolado.

Embora exista diferença de crescimento das árvores em solo subsolado e não subsolado, a análise estatística não comprovou esta observação.

\section{REFERÊNCIAS BIBLIOGRÁFICAS}

BRASIL. MINISTÉRIO AGRICULTURA. Divisão de Pesquisa Pedológica. Levantamento de Reconhecimento dos Solos do Estado do Rio Grande do Sul. Recife: 1973. 451p. (Boletim Técnico $\mathrm{n}^{\mathrm{o}} 30$ ). 
FAO. EI Eucalipto en la repoblacion forestal. Roma, FAO, 1981.723p.

FINGER,C.A.G. Ein Beitrag zur Ertragskund von Eucalyptus grandis und Eucalyptus saligna in Sudbrasilien. Wien: Universitat fuer Bodenkultur, 1991. 138p.

GUTTIERREZ de La LAMA. Atlas del Eucalipto. Sevilla: Ministério de Agricultura - Instituto Nacional de Invenstigaciones Agrárias -Instituto para la Concervacion de la Naturaleza, 1976. $4 \mathrm{~V}$.

HUSCH, B.; MULLER, C.; BEERS, T.W. Forest Mensuration. New York: John Wiley. 1982. 402p.

KAPLAN, J. Der Eukalyptus-Anbau in Israel. AFZ. 24-26. p.622-623. 1989.

MANGIERI, H.R.; DIMITRI, M.J. Los eucaliptos en la silvicultura. Buenos Aires: Acme., 1971. $226 \mathrm{p}$.

MORENO. J.A. Clima do Rio Grande do Sul. Porto Alegre: Secretaria da Agricultura - RS, 1961 . $41 \mathrm{p}$.

MOTA, F.S.; BELSDORF, M.I.C.; GARCEZ, J.R .B. Zonemamento Agroclimático do Rio Grande do Sul e Santa Catarina - Normas Agroclimáticas. Pelotas: Ministério da Agricultura, 1971. 80p. (Vol. I, Circular no 50).

POYNTON, R. J. Research the silviculture of Eucaliptos grandis (saligna) in the Northern Transvaal. South African Forestry Journal. 55: 10-20. 1965.

SCHUMACHER, M. V. Naehrstoffkreislauf in verschiedenen bestaenden von Eucaliptos saligna (Smith), Eucaliptos dunnii (maiden) und Eucaliptos globulus (Labillardiere) in Rio Grande so Sul, Brasilien. Wien. Universitaet fuer Bodenkultur. 1995. 164 p. (Tese de Doutorado)

SKOLMEN, R.G. Growth and yield of some Eucalyptus of interest to California. In: Proceedings of a Workshop on Eucalyptus in California. Sacramento, Pacific Southwest Forest and Range Experiment Station, General Tech. Rep. PSW-6p. 49-57.1984. 